The Egyptian Journal of Hospital Medicine (January 2019) Vol. 74 (3), Page 497-503

\title{
Relation between Lactate in Vaginal Fluid and Time to Spontaneous Onset of Labour for Women with Suspected Prelabour Rupture of the Membranes
}

\author{
Abd-Elmonem M. Zakaria, Mofeed F. Mohammed, Abdelhakeem O. Shehab \\ Department of Obstetrics and Gynecology,Faculty of Medicine, Al-Azhar University \\ Corresponding author: Abdelhakeem O. Shehab; Mobile: 01064049181; Email: drshehabshehab@yahoo.com
}

\begin{abstract}
Background: investigation of the relationship between lactate level in vaginal fluid and the latent phase of labour in pregnancies is complicated by preterm premature rupture of membranes (PPROM). To assess whether lactate determination in vaginal fluid can predict, onset of labour for women with suspected prelabour upture of the membranes (PROM). Patient and Methods: 110 pregnant women with history of PPROM recruited from the outpatient clinic and emergency room in EL Hussein Hospitals and Om El Masreen Hospital during the period from February 2018 till August 2018. All women underwent sterile speculum examination; then $5 \mathrm{ml}$ of sterile saline solution was injected in the posterior vaginal fornix using a sterile speculum and $2 \mathrm{ml}$ of the injected saline was withdrawn with the same syringe for lactate Measurement. Results: the best cutoff point of vaginal fluid lactate concentration as a predictor of onset of labor within 48 hours after PPROM was $4.7 \mathrm{mmol} / \mathrm{L}$ above which the onset of labor within 48 hours was likely with a sensitivity of $95.4 \%$, specificity of $91.3 \%$, a positive predictive value of $97.7 \%$, a negative predictive value of $84 \%$, an overall accuracy of $94.6 \%$, a positive LR of 10.97 and a negative LR of 0.05 . Conclusion: lactate determination in vaginal fluid seems promising as a tool to predict onset of labor within 48hours in women with PPROM. The best cutoff point of vaginal fluid lactate concentration as a predictor of onset of labor within 48 hours after PPROM was $4.7 \mathrm{mmol} / \mathrm{L}$.
\end{abstract}

Keywords: amniotic fluid, lactate, PROM, spontaneous onset of labour.

\section{Introduction}

Premature rupture of membranes (PROM) is defined as leakage of amniotic fluid beginning at least 1 hour prior to the onset of labor at any gestational age. Preterm premature rupture of membranes is defined as PROM that occurs before 37 weeks gestation (1). PROM is an important obstetric problem, it occurs in $10 \%$ of all gestation and about $2-4 \%$ of preterm pregnancies, which is responsible for $30 \%$ of all preterm birth. Management of patients with PROM, regardless the gestational age, remains controversial ${ }^{(2)}$.The interval between PROM and time to onset of labor is referred to as latency period, as this period tends to increase the risk of maternal and fetal infection increses, maternal infection is termed chorioamnionitis which occurs in 3-5\% of cases of PROM. While fetal infection occurs in about $5 \%$ of all cases of PROM and about 15-20\% in those with chorioamnionitis. Fetal infection may occur as septicemia, pneumonia, urinary tract infection, local infection such as omphalitis (infection of the umbilical cord) or conjunctivitis (3). Other complications that may be associated with PROM include umbilical cord prolapse in about $1.5 \%$ of cases of PROM. Placental abruption, caesarean delivery, postpartum hemorrhage and postpartum infection ${ }^{(2)}$.Correct diagnosis of PROM had great importance because failure of diagnosis can lead to unwanted obstetric complications like chorioamnionitis and preterm birth, on the other hand over diagnosis can lead to unnecessary interventions like hospitalization or induction of labor ${ }^{(4)}$.Traditionally the diagnosis of membranes was rupture clinical in over $90 \%$ of cases, being confirmed based on the presence of suspicious history, or ultra-sonographic finding followed by documentation of fluid passing from the cervix ${ }^{(5)}$.These traditional diagnostic methods have some limitation and cannot be applied to all patients with $100 \%$ accuracy ${ }^{(1)}$. The absence of non invasive gold standard test for diagnosis of membranes rupture leads to search for an alternative biochemical markers which have high amniotic concentration but low vaginal fluid concentration e.g. prolactin, alpha fetoprotein, insulin like growth factor binding protein-1, fetal fibronectin, diamine oxidase and $\mathrm{B}-\mathrm{HCG}^{\left({ }^{(6)}\right.}$.Lactate was the end product of anaerobic metabolism, usually its production takes place in hypoxic tissue, but can be produced under aerobic conditions ${ }^{(7)}$. Lactate was produced in the myometrium and chorio-decidua and transferred to AF across the membranes, but the main source of lactate was the fetus mainly through urine and lung excretion ${ }^{(8)}$. Lactate concentration 
in amniotic fluid was 7-9 mmol/L which was four to six times higher than its level in the maternal and fetal blood, so that vaginal fluid lactate may help in the diagnosis of PROM ${ }^{(9)}$. Lactate had also been reported to occur in high concentration in amniotic fluid, (7-9 mmol/l), which is four to six times higher than in maternal or fetal blood. The source of the amniotic fluid lactate had been suggested to be the fetus, mainly through urine and lung fluid excretion. A lactate concentration $\geq 4.5 \mathrm{mmol} / \mathrm{l}$ in vaginal fluid, is a reliable test for rupture of the membranes in pregnancies of 34 weeks of gestation or more ${ }^{(8)}$.There was a significant association between positive lac test and spontaneous onset of labour within 48 hours in late gestations that is $\geq$ 34 weeks ${ }^{(9)}$. Prediction of spontaneous onset of labour was even more valuable in preterm pregnancies, when antenatal steroids may be administered (8). PPROM between 34 and 37 weeks, in Sweden studies, presented clinical practice was to wait 48 hours to allow spontaneous onset of labour. After 48 hours, induction of labour was suggested. The woman may be kept in hospital. A negative Lac test gave strong support for 'not PROM' and not laboring within 48 hours and controls could be omitted. The woman could be sent back home and wait for spontaneous onset of labour later on. Having a positive Lac test suggested onset of labour within 24 hours in $79 \%$ of cases ${ }^{\left({ }^{9}\right)}$. Lactate determination in vaginal fluids was a valid method for prediction of onset of labour within 24 and 48 hours. High lactate is more strongly associated with spontaneous onset of labour than with visible $\mathrm{AF}{ }^{(9)}$. A high lactate concentration in vaginal fluid is strongly associated in a woman with suspected PPROM will commence onset of labor within 48 hours ${ }^{(\mathbf{1 0})}$.

\section{Aim of the Work}

The aim of the study was to assess the association between lactate concentration in vaginal fluid and time to spontaneous onset of labor in women with sure preterm premature rupture of membranes.

\section{Patients and Methods}

This prospective observational study was carried out in EL Hussein Hospitals and Om El Masreen Hospital during the period from February 2018 till August 2018 and it included 110 pregnant women with history of PPROM recruited from the outpatient clinic and emergency room during the period from February 2018 till August 2018 . An oral, informed consent was obtained from all participants. The study was approved by the Ethics Board of Al-Azhar University.

\section{Inclusion Criteria:}

- Singleton pregnancy.
- Cephalic Presentation.

- Gestational age between 28-36 weeks.

- History of PPROM.

- Cervical dilatation $<4 \mathrm{~cm}$.

- Clear vaginal fluid with no signs of vaginal infection.

- No pyrexia.

\section{Exclusion Criteria:}

- Uterine contractions.

- Women had been delivered in another hospital.

- Women had been delivered by induction of labor.

- Women had been delivered by emergency caesarean section before the end of latent phase of labor.

All patients enrolledin this study were subjectedto the following:

Full history was taken for all patients especially for:

1. Exact date of last menstrual period to calculate the expected date of delivery.

2. Full obstetric history.

3. History of passage of watery vaginal discharge.

4. Past history of premature rupture of

membranes, abortion, previous caesarean section.

5- General and abdominal examinations.

All women underwent sterile speculum examination and $\mathrm{AF}$ pooling with or without valsava maneuver was note.

Then $5 \mathrm{ml}$ of sterile saline solution was injected in the posterior vaginal fornix using a sterile speculum and $2 \mathrm{ml}$ of the injected saline was withdrawn with the same syringe for lactate measurement.

\section{Method}

For lactate determination, the commercially available Lactate Pro.(an electrochemical test strip method) was used an (accutrend ${ }^{\circledR}$ lactate) type 3012522 an electrochemical equipment of Roche company and we used (BM-Lactate) as test strips for the quantitative determination of lactate in amniotic fluid.The test needed only $5 \mu \mathrm{l}$ of fluid for the analysis. It was carried out at the bedside and the result was available after 60 seconds.

\section{Reaction Principle:}

How the test works: each test strip has a test area containing detection reagents. When amniotic fluid is applied, a chemical reaction takes place and the test area changes colour. The Accutrend ${ }^{\circledR}$ Lactate recorded this change in colour and converts the measured signal to the displayed result using the data previously entered by means of the code strip. 
Test principle: the applied amniotic fluid seeps through the yellow protective mesh into a glass fibre fleece. Lactate is determined by reflectance photometry at a wave length of $657 \mathrm{~nm}$ via a colorimetric lactate-oxidase mediator reaction.

$$
\begin{aligned}
& \text { L-lactate }+ \text { mediator }_{\text {form } \mathrm{I}}-\mathrm{LOD} \rightarrow \text { pyruvate }+ \text { mediator }_{\text {reduced }} \\
& \text { Mediator } \text { reduced }+2,18 \text {-phosphomolybdate } \rightarrow \text { molybdane blue }+ \text { mediator form II }
\end{aligned}
$$

\begin{abstract}
Components per test: lactate oxidase (rec.Aerococcus viridans) 1,9U;N,N-bis-(2hydroxyethyl)-4-hydroximino-cyclohexa-2,5-

dienylidene) ammonium-chloride $7.2 \mu \mathrm{g}$; phosphomolybdate $11.4 \mu \mathrm{g}$.
\end{abstract}

Performance characteristics: the data for BM-Lactate were determined in series of tests during evaluation. The majority of the data for the test were within the given ranges. Repeatability (within-series imprecision): CV (coefficient of variation) $5.5 \%$ in the normal range, $5 \%$ in the higher range. Reproducibility (day-to-day imprecision). CV $4.8 \%$ in the low range, $3.3 \%$ in the pathological range; sample material: control solutions. Accuracy (methods comparisons, mmol/l: regression equations, $\mathrm{n}$ samples, correlation coefficients $\mathrm{r}$ ) $\mathrm{y}=0.957 \mathrm{x}-0.042$ and $1.039 x+0.325$, respectively, $(n=77-147, r=$ 0.970), reference method $\mathrm{x}$ : Test Combination Lactate, Roche Diagnostics. Detection limit (lowest value detected) $0.8 \mathrm{mmol} / \mathrm{l}$ and $0.7 \mathrm{mmol} / \mathrm{l}$. respectively.

\section{Amniotic fluid index calculation Then all the patients were followed up until delivery}

Accutrend ${ }^{\circledR}$ lactate type 3012522 an electrochemical equipment of Roche company and we used BM-Lactate as test strips for the quantitative determination of lactate in amniotic fluid.

\section{Sample size justification:}

Sample size was calculatedby using EpiInfo® version 6.0, setting the power at $80 \%$ and significance level at 0.05 . The standard deviation of the latency period for preterm prelabor rupture of membranes is 74.5 hours (11). A worthwhile, difference in the latency period was assumed to be 48 hours. Calculation according to these values produced minimal sample size of 104 cases. Assuming a drop-out rate of $5 \%$, the total sample size was 110 cases.

\section{Statistical analysis:}

Measured observations were spread on worksheet of Microsoft ${ }^{\circledR}$ Excel ${ }^{\circledR}$ version 2007. Statistical analysis was performed using Statistical Package for Social Sciences (SPSS $®$ ) for Windows $®$ version 15.0. Description of quantitative variables were represented in terms of mean, standard deviation $( \pm \mathrm{SD})$ and range. Description of qualitative variables was represented in terms of no. and percentages (\%). Unpaired student's t-test was used for comparing parametric data and Chi-square (X2) test was used for comparing non parametric data. ROC (Receiver Operator Characteristic) curve was used to find out the overall predictivity of parameters and to find out the best cutoff value with detection of sensitivity, specificity at this cutoff value. Pearson correlation coefficient ( $\mathrm{r}$ ) test was applied to reveal if there was any correlation. A probability value ( $\mathrm{p}$ value) more than 0.05 was considered non-significant, a probability value ( $\mathrm{p}$ value) less than 0.05 was considered significant and a probability value $(\mathrm{p}$ value) less than 0.001 was considered highly significant. Accuracy was represented using the terms sensitivity, specificity, positive predictive value, negative predictive value and overall accuracy.

\section{Results}

Table 1: characteristics of the patients with history of PPROM

\begin{tabular}{|l|l|}
\hline $\begin{array}{l}\text { Maternal Age (Years) Range } \\
\text { Median }\end{array}$ & $19-41$ \\
\hline Parity & $0-6$ \\
Range & $1(0-3)$ \\
Median & $29.2-36.1$ \\
\hline Gestational Age at PPROM (Weeks) & 32.6 \\
Range & \\
Median & \\
\hline
\end{tabular}

This table showed that the median age of patients with history of PPROM was 30 years (Range: 19 -41 years). The median parity was 1 (Range: $0-6$ ). The median gestational age at PPROM was 32.6 weeks (range: $29.2-36.1$ weeks).

Table 2: vaginal fluid lactate concentration

\begin{tabular}{|l|l|}
\hline Vaginal fluid lactate concentration & $1.25-9.9$ \\
\hline (mmol/L) Range Median & 2.35 \\
\hline
\end{tabular}

This table showed that the median vaginal fluid lactate concentration was $2.35 \mathrm{mmol} / \mathrm{L}$ (range: $1.25-9.9 \mathrm{mmol} / \mathrm{L})$ 
Relation between Lactate in Vaginal Fluid and Time to Spontaneous Onset of Labour...

Table 3: characteristics of patients with history of PPROM at onset of labor

\begin{tabular}{|c|c|}
\hline $\begin{array}{c}\text { Vaginal fluid lactate concentration (mmol/L) } \\
\text { Range } \\
\text { Median }\end{array}$ & $1.25-9.9$ \\
\hline
\end{tabular}

This table showed that the median vaginal fluid lactate concentration was $2.35 \mathrm{mmol} / \mathrm{L}$ (range: $1.25-$ $9.9 \mathrm{mmol} / \mathrm{L})$

Table 4: characteristics of patients with history of PPROM at onset of labor .

\begin{tabular}{|l|l|}
\hline $\begin{array}{l}\text { Gestational Age at onset of labor (Weeks) } \\
\text { Range } \\
\text { Median }\end{array}$ & \multicolumn{1}{c|}{$29.4-36.533 .4$} \\
\hline $\begin{array}{l}\text { Mode of Delivery [No. (\%)] Vaginal delivery Emergency Cesarean section } \\
\text { Vacuum extraction }\end{array}$ & $\begin{array}{l}\text { 94/110 (85.5\%) 14/110 (12.7\%) } 2 / 110 \\
(1.8 \%)\end{array}$ \\
\hline
\end{tabular}

This table showed that the median gestational age at delivery was 33.1 weeks (range: 29.4-36.5 weeks). $94(85.5 \%)$ women with history of PPROM delivered vaginally, 14 (12.7\%) delivered by emergency CS, while $2(1.8 \%)$ delivered by vacuum extraction.

Table 5: lactate concentration in vaginal fluid and onset of labor within 24 hours and 48 hours

\begin{tabular}{|c|c|c|}
\hline & $\begin{array}{l}\text { Lactate } \\
>4.5 \mathrm{mmol} / \mathrm{l}\end{array}$ & $\begin{array}{l}\text { Lactate } \\
<4.5 \mathrm{mmol} / \mathrm{l}\end{array}$ \\
\hline Onset of labor <24hours [No. (\%)] & $52 / 86(60.4 \%)$ & $2 / 24(8.3 \%)$ \\
\hline Onset of labor <48hours [No. $(\%)]$ & $69 / 86(80.2 \%)$ & $4 / 24(16.6 \%)$ \\
\hline Median latency Period (Hours) & 14.5 & 75.6 \\
\hline
\end{tabular}

This table showed that $52(60.4 \%)$ patients with history of PPROM and lactate concentration $>4.5 \mathrm{mmol} / \mathrm{l}$, (according to preset cut-off value of $>4.5 \mathrm{mmol} / \mathrm{L}$, retrieved from a study conducted by Wiberg-Itzel et al. ${ }^{\left({ }^{(10)} \text { had }\right.}$ an onset of labor within 24 hours while, $2(8.3 \%)$ patients with history of PPROM and lactate concentration $<4.5 \mathrm{mmol} / \mathrm{l}$ had an onset of labor within 24 hours. $69(80.2 \%)$ patients with history of PPROM and vaginal lactate concentration $>4.5 \mathrm{mmol} / \mathrm{l}$ had an onset of labor within 48 hours and $4(16.6 \%)$ patients with lactate concentration $<4.5 \mathrm{mmol} / \mathrm{l}$ had an onset of labor within 48 hours, The median latency period was 14.5 hours in patients with vaginal lactate concentration $>4.5 \mathrm{mmol} / 1$; and 75.6 hours in patients with vaginal lactate concentration $<4.5 \mathrm{mmol} / \mathrm{l}$.

Table 6: correlation between latency period and other variables in patients with history of PPROM

\begin{tabular}{|c|c|c|}
\hline & \multicolumn{2}{|c|}{ Latency Period } \\
\hline & $\mathbf{R} *$ & $\mathbf{P}$ \\
\hline Maternal Age & -0.190 & $>0.05$ (NS) \\
\hline Parity & -0.139 & $>0.05(\mathrm{NS})$ \\
\hline History of PPROM in previous pregnancy (ies) & -0.124 & $>0.05(\mathrm{NS})$ \\
\hline Gestational Age at PPROM & -0.311 & $0.001(\mathrm{~S})$ \\
\hline Vaginal Fluid Lactate Concentration & -0.716 & $<0.001$ (HS) \\
\hline Mode of Delivery & $0.116 * *$ & $>0.05(\mathrm{NS})$ \\
\hline Birth Weight & 0.312 & $0.001(\mathrm{NS})$ \\
\hline Need for NICU Admission & -0.300 & $0.004(\mathrm{~S})$ \\
\hline
\end{tabular}

* Pearson's correlation coefficient

** Spearman's rank correlation coefficient

NS non-significant - S significant - HS highly significant

This table showed that there was a significant negative correlation between latency period and vaginal fluid lactate concentration $(\mathrm{r}=-0.716, \mathrm{p}<0.001)$, gestational age at PPROM $(\mathrm{r}=-0.311, \mathrm{p}=0.001)$ and need for NICU admission ( $\mathrm{r}=-0.3, \mathrm{p}=0.004)$. There was, however, a non-significant correlation between latency period and each of maternal age, parity, history of PPROM in previous pregnancy(ies), mode of delivery and birth weight.

Table 7: correlation between Latency Period and Vaginal Fluid Lactate concentration according to different gestational ages

\begin{tabular}{|c|c|c|c|}
\hline & \multicolumn{3}{|c|}{ Latency Period } \\
\cline { 2 - 4 } & $\begin{array}{c}\text { GA at PPROM } \\
\mathbf{2 8}-<\mathbf{3 2} \text { weeks } \\
(\mathbf{n}=\mathbf{3 6})\end{array}$ & $\begin{array}{c}\text { GA at PPROM } \\
\mathbf{3 2}-<\mathbf{3 4}(\mathbf{n}=\mathbf{3 8})\end{array}$ & $\begin{array}{c}\text { GA at PPROM } \\
\mathbf{3 4 - 3 6}(\mathbf{n}=\mathbf{3 6})\end{array}$ \\
\hline Vaginal fluid lactate concentration $(\mathrm{mmol} / \mathrm{L}) \mathrm{r}^{*}$ & 0.815 & 0.663 & 0.614 \\
$\mathrm{P}$ & $<0.001(\mathrm{HS})$ & $<0.001(\mathrm{HS})$ & $<0.001$ (HS) \\
\hline
\end{tabular}

* Pearson's correlation coefficient HS highly significant

This table showed that the correlation between latency period and vaginal fluid lactate concentration was higher at smaller gestational ages at PPROM.

Table 8: difference between patients who had an onset of labor within 48 hours and patients who had an onset of labor after 48 hours concerning vaginal fluid lactate concentration 
Abd-Elmonem Zakaria et al.

\begin{tabular}{|l|c|c|c|}
\hline $\begin{array}{l}\text { Vaginal fluid lactate } \\
\text { concentration }\end{array}$ & & & \\
(mmol/L) & $3.5-9.9$ & $2.25-5.02$ & $<0.001$ \\
$\quad$ Range: & $7.12 \pm 1.66$ & $3.76 \pm 0.78$ & HS \\
\hline Mean \pm SD: & & & \\
\hline
\end{tabular}

* Analysis using independent student's t-test HS highly significant

This table showed that the median vaginal fluid lactate concentration was significantly higher in patients who had an onset of labor within 48 hours after PPROM when compared to patients who had an onset of labor after 48 hours $7.12 \pm 1.66 \mathrm{mmol} / \mathrm{L}$ vs. $3.76 \pm 0.78 \mathrm{mmol} / \mathrm{L}$, respectively, $(\mathrm{p}<0.001)$.

Table 9: area under ROC curve for vaginal fluid lactate concentration as predictor of onset of labor within 48 hours

\begin{tabular}{|l|c|c|c|}
\hline $\begin{array}{l}\text { Vaginal fluid lactate concentration as } \\
\text { predictor of delivery within } 48 \text { hours }\end{array}$ & AUC & $\mathrm{P}$ & $\begin{array}{c}95 \% \\
\text { Confidence Interval }\end{array}$ \\
\cline { 2 - 4 } & 0.980 & $\begin{array}{c}<0.001 \\
\text { (HS) }\end{array}$ & 0.958 to 1.001 \\
\hline
\end{tabular}

This table showed that receiver operator characteristics (ROC) curve was constructed for vaginal fluid lactate concentration as predictor of onset of labor within 48 hours. Area under curve (AUC) was 0.980 [p<0.001, 95\% CI (0.958 to 1.001$)]$.

Table 10: best cutoff point for vaginal fluid lactate concentration as predictor of onset of labor within 48 hours

\begin{tabular}{|c|c|c|c|c|c|c|c|c|}
\hline \multirow{2}{*}{$\begin{array}{c}\text { Vaginal fluid } \\
\text { lactate } \\
\text { concentration as } \\
\text { predictor of } \\
\text { delivery within } 48 \\
\text { hours } \\
\end{array}$} & $\begin{array}{c}\text { Best } \\
\text { Cutoff }\end{array}$ & Sensitivity & Specificity & PPV & NPV & Accuracy & +ve LR & $\begin{array}{l}\text {-ve } \\
\text { LR } \\
\end{array}$ \\
\hline & $\begin{array}{c}4.7 \\
\mathrm{mmol} / \mathrm{L}\end{array}$ & $95.4 \%$ & $91.3 \%$ & $97.7 \%$ & $84 \%$ & $94.6 \%$ & 10.97 & 0.05 \\
\hline
\end{tabular}

This table showed that the best cutoff point of vaginal fluid lactate concentration was $4.7 \mathrm{mmol} / \mathrm{L}$ above which an onset of labor within 48 hours is likely with a sensitivity of $95.4 \%$, specificity of $91.3 \%$, a positive predictive value of $97.7 \%$, a negative predictive value of $84 \%$, an overall accuracy of $94.6 \%$, a positive LR of 10.97 and a negative LR of 0.05 .

\section{Discussion}

PPROM represented one of the common obstetric problems that complicate approximately 3 $5 \%$ of all pregnancies and accounts for one-third of all preterm births ${ }^{(12)}$. This current prospective observational study was conducted in both EL Hussein Hospitals and Om El Masreen Hospital during the period from February 2018 till August 2018.A total 110 women, with history of PPROM, were included in this study.In the current study, the median age of patients with history of PPROM was 30 years (range: 19-41 years). The median parity was 1 (range: 0-3). The median gestational age at onset of PPROM was 32.6 weeks (range: $29.4-36.1$ weeks).These results were similar to the results reported by Wiberg-Itzel et al. ${ }^{(10)}$ on 81 patients with suspected history of PPROM at 20-36 completed weeks of gestation, who found that the median maternal age was 32 years (range: $20-$ 41years), the median gestational age at PPROM was 33.1 weeks ( 20.1-36.5 weeks).In the current study, the median vaginal fluid lactate concentration was 2 $.35 \mathrm{mmol} / \mathrm{L}$ (range: 1.25 - $9.9 \mathrm{mmol} / \mathrm{L}$ ).

These results are similar to that reported by Wiberg-Itzel et al. ${ }^{(10)}$ who found that the median vaginal fluid lactate concentration was $2 \mathrm{mmol} / \mathrm{L}$ (range: $0.5-15.6 \mathrm{mmol} / \mathrm{L}$ ). But, the study of $\mathbf{Y o s s} \mathbf{f}^{\text {(14) }}$ found that the median vaginal fluid lactate concentration was $3.8 \mathrm{mmol} / \mathrm{L}$ (range: 0.8$6.9 \mathrm{mmol} / \mathrm{L})$.
In the present study the median gestational age at onset of labor was 33.4 weeks (Range: 29.4 36.5 weeks), which is inconsistent with the results noted by Wiberg-Itzel et al. ${ }^{(10)}$. Jaiswar et al. ${ }^{(13)}$ found that the median gestational age at onset of labor was 36 weeks (range: 23.6 - 37.5 weeks); Yossef ${ }^{(14)}$ found that the median gestational age at onset of labor was 37 weeks (range: 37 - 38 weeks) This may be due to different median gestational age at PPROM between the current study and WibergItzel et al. ${ }^{(10)}$, Jaiswar et al. ${ }^{(13)}$, Yossef ${ }^{(14)}$, Nazari et al. ${ }^{(15)}$ (32.6, 33.1 weeks) respectively.In the current study 94 (85.5\%) delivered vaginally, 16 (14.5\%) delivered by emergency Cesarean section,

However, Wiberg-Itzel et al ${ }^{(\mathbf{1 0})}$ found that $53(65.5 \%)$ delivered vaginally, $23(28.5 \%)$ delivered by emergency cesarean section, while $5(6 \%)$ by vacuum extraction.Yossf ${ }^{(\mathbf{1 4})}$ found that $62(76.3 \%)$ delivered vaginally $38(23.7 \%)$ delivered by emergency cesarean section. In the current study, $80.2 \%$ (69/86) patients with history of PPROM and vaginal lactate concentration $\geq 4.5 \mathrm{mmol} / 1$, (according to preset cut-off value of $\geq 4.5 \mathrm{mmol} / \mathrm{L}$, retrieved from a study conducted by Wiberg-Itzel, et al. ${ }^{(10)}$ had an onset of labor within 48 hours while $16.6 \%$ (4/24); patients with history of PPROM and lactate concentration $<4.5 \mathrm{mmol} / \mathrm{l}$ had an onset of labor within 48 hours. However, Wiberg-Itzel et al. (10) found that $87.3 \%(20 / 23)$ with lactate 
Relation between Lactate in Vaginal Fluid and Time to Spontaneous Onset of Labour...

concentration $\geq 4.5 \mathrm{mmol} / \mathrm{L}$ had onset of labor within 48 hours after PPROM. While 5\% (3 / 58) with lactate concentration $<4.5 \mathrm{mmol} / \mathrm{L}$ had onset of labor within; 48 hours after PPROM but, Jaiswar et al. ${ }^{(13)}$ found that the lactate levels of $\geq 5.0 \mathrm{mmol} / \mathrm{L}$, $81.0 \%$ of patients had spontaneous onset of labour within 48 hours after PROM. In the current study, the median latency period was 14.5 hours in patients with history of PPROM and vaginal lactate concentration $\geq 4.5 \mathrm{mmol} / \mathrm{l}$, while 75.6 hours in patients with history of PPROM and vaginal lactate concentration $<4.5 \mathrm{mmol} / 1$.These results are similar to Wiberg-Itzel et al. ${ }^{(10)}$, Jaiswar et al. ${ }^{(13)}$ who found that the median latency period was 13.6hours in patients with lactate concentration $\geq 4.5 \mathrm{mmol} / \mathrm{L}$ and 79 hour in patients with lactate concentration $<4.5 \mathrm{mmol} / \mathrm{L}$ and visible AF. In the present study, there was a significant negative correlation between latency period and vaginal fluid lactate concentration which agrees with Wiberg-Itzel $\boldsymbol{e t}$ al. ${ }^{(9)}$, Wiberg-Itzel et al. ${ }^{\left({ }^{10)}\right.}$ who found that high lactate concentration $(>4.5 \mathrm{mmol} / \mathrm{L})$ in vaginal fluid were, compared to lower concentration $(<4.5 \mathrm{mmol} / \mathrm{L})$, associated with shorter latency period.In this current study, there was a significant negative correlation between latency period and gestational age at PPROM ( $\mathrm{r}=-0.311, \mathrm{p}=0.001)$ which agree with the results published by Wiberg-Itzel et al. ${ }^{(9)}$, Aziz et $a l .{ }^{(16)}$, Wiberg-Itzel et al. ${ }^{(10)}$, Melamed et al. ${ }^{17)}$ .These studies reported that the duration of latency period was inversely related to gestational age at time of PPROM.In this current study, the correlation between latency period and vaginal fluid lactate concentration was higher at smaller gestational ages at PPROM. $(\mathrm{r}=0.815,0.663,0.614, \mathrm{p}<0.001$, for gestations $28-<32$ weeks, $32-<34$ weeks, $34-<37$ weeks, respectively. This indicates that vaginal fluid lactate concentration was best useful as the gestational age at PPROMdecreases.These results are similar to Wiberg-Itzel et $\boldsymbol{a l} .{ }^{(\mathbf{1 0 )}}$ who found that the latency period and vaginal lactate concentration higher at gestational age $<30$ weeks. In the present study, there was a significant negative correlation between latency period and need for NICU admission $(\mathrm{r}=-0.3, \mathrm{p}=0.004)$. These results are consistent with the results published by Manuck $\boldsymbol{e t}$

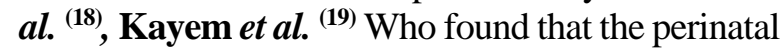
outcomes after PPROM did not worsen with longer latency period. Moreover, the need for NICU admission decreases and overall survival and survival rates without major morbidities were high. In the current study, there was a non-significant correlation between latency period and each of age, parity, history of PPROM in previous pregnancy(ies), mode of delivery and birth weight. These results are consistent with the results reported by Wiberg-Itzel et $a l .{ }^{(10)}$, Manuck $e t$ al. ${ }^{(18)}$ and
Deering et al. ${ }^{(20)}$ who found no association between latency period and maternal age, parity, mode of delivery previous PPROM, birth weight. However, these results disagree with Melamed et al. ${ }^{(17)}$ who found that nulliparity was associated with shorter latency period. In the current study the median vaginal fluid lactate concentration was significantly higher in patients who had an onset of labor within 48 hours after PPROM when compared to patients who an onset of labor after 48 hours. These results agree with the results reported by Wiberg- Itzel $\boldsymbol{e t}$ al. ${ }^{(10)}$ Jaiswar et al. ${ }^{(13)}$ who found that the odds of being in labor within 48 hours after PPROM were almost 20 times higher among women with high lactate concentration than among those with lower lactate concentration.In the current study the best cutoff point of vaginal fluid lactate concentration as a predictor of onset of labor within 48 hours after PPROM was $4.7 \mathrm{mmol} / \mathrm{L}$ above which the onset of labor within 48 hours was likely with a sensitivity of $95.4 \%$, specificity of $91.3 \%$, a positive predictive value of $97.7 \%$, a negative predictive value of $84 \%$, an overall accuracy of $94.6 \%$, a positive LR of 10.97 and a negative LR of 0.05 . These resulst are similar to the results reported by Wiberg- Itzel et al. ${ }^{(10)}$ found that vaginal fluid lactate concentration $\geq 4.5 \mathrm{mmol} / \mathrm{L}$ was a cutoff value for prediction of onset of labor within 48 hours or not . With a sensitivity of $87 \%$, specificity of $93 \%$, a positive predictive value of $83 \%$, a negative predictive value of $72 \%$, a positive LR of 12.6 and a negative LR of 0.14 .

\section{Conclusion}

Lactate determination in vaginal fluid seems promising as a tool to predict onset of labor within 48hours in women with PPROM. The best cutoff point of vaginal fluid lactate concentration as a predictor of onset of labor within 48 hours after PPROM was $4.7 \mathrm{mmol} / \mathrm{L}$.

\section{References}

1. Buyukbayrak E, Turan C, Unal O et al. (2004): Diagnostic power of vaginal washing fluid prolactin assy as an alternative method for the diagnosis of premature rupture of the membranes. The Journal of Maternal Fetal Neonatal Medicine, 15: 120-125.

2. Modena A, Kaihura C and Fieni S (2004): Prelabor rupture of membranes: recent evidence. Acta Biomed. Ateneo. Parmense, 75(2): 9-12.

3. Benedetto $\mathrm{C}$, Tibaldi $\mathrm{C}$, Marozio $\mathrm{L}$ et al. (2004): Cervicovaginal infection during pregnancy: epidemio-logical and microbiological aspect. J. Matren. Fetal Neonatal. Med., 16 (2): 9-12.

4. Kafali H. and Oksuzler C (2006): Vaginal fluid urea and creatinine in diagnosis of pre 
mature rupture of membranes. Arch Gynecol. Obstet., 12:1-4.

5. Kim Y, Park Y, Kwan $\mathrm{H}$ et al. (2005): Vaginal fluid beta-human chorionic gonadotrophin level in the diagnosis of premature rupture of membranes. Acta Obstet. Gynecol. Scand., 84: 802-805.

6. Esim E, Taran C, Unal O et al. (2003): Diagnosis of premature rupture of membranes by identification of Beta-HCG in vaginal washing fluid. Eur. J. Obstet. Gynecol. Reprod . Bio., 107: 37-40.

7. Nordstrom L (2001): Lactate measurement in scalp and cord arterial blood. Curr. Opin. Obstet. Gynecol., 13: 141-145.

8. Wiberg-Itzel E, Cnattingius $S$ and Nordstrom L et al. (2005): Lactate determination in vaginal fluid: a new method in the diagnosis of prelabor rupture of membranes. BJOG., 112:754-758.

9. Wiberg-Itzel E, Peterson $\mathbf{H}$, Cnattingius $\mathbf{S}$ et al. (2006): Association between lactate in vaginal fluid and time to spontaneous onset of labor for women with suspected prelabor rupture of membranes. BJOG., 113: 14261430.

10. Wiberg-Itzel E, Peterson $\mathrm{H}$, Cnattingius $\mathrm{S}$ et al. (2009): Prediction of time to spontaneous onset of labour with lactate concentration in vaginal fluid in women with suspected preterm prelabour rupture of the membranes. BJOG., 116:62-66.

11. Steer $P$ (2005): The epidemiology of preterm labor-a global perspective. Journal of Perinatal Medicine, 33(4):273-280.

12. Simhan HN and Canavan TP (2005): Preterm premature rupture of membranes: diagnosis, evaluation and management strategies. BJOG. An International Journal of Obstetrics and Gynaecology, 112:32-7.

13. Jaiswar S, Natu S, Gupta A et al. (2013): Association between lactate levels in vaginal fluid and time of spontaneous onset of labour in suspected cases of prelabour rupture of membranes. Am. J.Obstet. Gynecol. of India, 63(3):182-185.

14. Yossef S (2009): Lactate concentration in vaginal fluid as a predictor for labour for women with suspected prelabour repture of the membranes, Thesis submitted for partial fulfillment of Master Degree in Obsterics and Gynecology, Faculty of Medicine, Ain Shams University.Cairo.

15. Nazari N, Ahmadi M, Mazani $M$ et al. (2012) The diagnostic value of lactate level in the vaginal fluid for determining the premature rupture of membranes. Journal of Society for Development in Environment, 6: 12-19.. .

16. Aziz N, Cheng Y and Caughey A (2008) Factors and outcomes associated with longer latency in preterm premature rupture of membranes.Journal of Maternal-Fetal and Neonatal Medicine, 21(11): 821-825.

17. Melamed N, Hadar E, Ben-Haroush A et al. (2009): Factors affecting the duration of the latency period in preterm premature rupture of membranes. The Journal of Maternal-Fetal and Neonatal Medicine, 22(11):1052-1058.

18. Manuck $T$, Maclean $C$, Selver $R$ et al. (2009) :Preterm premature rupture of membranes: does the duration of latency influence perinatal outcomes? Am. J. Obstet. Gynecol., 201: 414:1-6.

19. Kayem G, Maillerd $F$ and Schmitz $T$ (2009): Prediction of clinical infection in women with preterm labour with intact membranes: A score based on ultrasonographic, clinical and biological markers. European Journal of Obstetrics and Gynecology Reproductive Biology, 145(1): 36-40.

20. Deering S, Patel N, Spong C et al. (2007): Fetal growth after preterm premature rupture of membranes: is it related to amniotic fluid volume? Journal of Maternal-Fetal and Neonatal Medicine, 20(5): 397-400. 